\title{
Influence of elements of "technological revolution" on efficiency of the investment and construction sphere
}

\author{
Olga Murashova ${ }^{1, *}$ \\ ${ }^{1}$ Moscow State University of Civil Engineering, 26, Yaroslavskoye shosse, Moscow, 129337, Russia
}

\begin{abstract}
The article describes a new view on the investment and construction area taking into consideration the influence of information technologies and innovations. The author has pointed out the basic aspects, which could allow making a break-through in management effectiveness, if being implemented in companies' business or in investment and construction projects. The article presents the definition of the investment and construction cycle as an integrator of innovation solutions. The paper contains the conclusion about the obvious sector development using active implementation of information modeling of the investment and construction project facilities.
\end{abstract}

\section{Introduction}

The volume growth, the increasing speed and intensity of data receive, or so called "information explosion", highlights the importance and relevance of information technologies. Scientific achievements in the area of information technologies actively affect the development of national economy basic sectors. Information is considered as the fourth basic resource equal to capital, land and manpower. Rapid development of technologies leads to re-thinking of business and management's core. Specialists discuss society and economic sectors dipping in the process of "technological revolution", its influence on all aspects of the society and make prognosis. For example, there are predictions of Raymond Kurzveil [1], who in particular predicts that virtual reality in conditions of "full dipping" will have formed by 2030 .

\section{Research methods}

The "technological revolution" era passes by cycles and gradually conquers new economic sectors. World is standing on the verge of new "technological mode" which is forming in developed nations, partially touching Russia. It is characterized by development and implementation of innovations and information technologies. Nanotechnology, micromechanics, hosted options, software packages with vast database sound familiar to everybody, the synthesis of achievements in these fields should lead, for example, to

*Corresponding author: olga mura@mail.ru 
creation of artificial intellect, and finally raise development to a completely new level of state, sector, society, city governing and company management [2]. The nature of this epoch is high speed of changing of various life aspects and, as the result, formation of new effective indexes and /or their transformation, e.g. "capitalization speed". Market players claim that any company, no matter whether it is a long-life cycle or newly created, could be viable on a market only if it complies the following:

- If a company creates a new business model and enters a market with it, the model should be improved and effective;

- The second factor that affects competitive ability is effectiveness of the workforce management what a company should build relations with in order to upgrade the personnel's skill;

- Another important factor is satisfying clients' needs and requirements; a company is supposed not to ask a consumer (individual, company) about improvements, but to be on consumer's side, collecting data and offering service.

It is suggested applying flexible management methods as models to secure company's capitalization (Agile, Scrum, Kanban etc.). These management methods are borrowed from IT sphere (IT - information technologies) and acknowledged by effective application in management in other economic sectors. Some companies acquired project methods of management, implemented elements of network planning and started using it effectively but some other companies, that transformed and came to the market with innovative business model following flexible management method, performed substantial results and significant efficiency growth. They can dispute long and find out how to use flexible management practices in the construction sector companies and their impact on the efficiency of companies, because some companies are introducing new management methods now, and time will tell how effective they will affect the results.

Nowadays, significant changes happen in personnel management field. Gradual new professional standards of relevant specialties, which settle minimum requirements to personnel, have been developed and implemented. Active implementation of information technologies leads to a strong demand of well-qualified personnel; though low-level workers remain relevant. Thus, redistribution of labor recourses requires specialists of informational technologies era, since the need for so called "middle class" have reduced. The tendency to the necessity of knowledge arises again.

\section{Results}

Some market players actively resist implementing innovations in the investment and construction field with its formed traditional principles (according to a great amount of market players). Construction has a long history, thus its processes and issues have been thoroughly analyzed. Designing, construction and upkeep methods have been formed and today they are put into practice. The introduction of IT technologies in the construction sector is a complex process, but the impending changes in speed, the growing demands for decision-making, the mobilization of large-scale projects will be accompanied by the appropriate development, implementation of digital technologies in design, business processes and the content of real estate.

AutoCAD, Revit, ArchiCAD and other remarkable software packages (software) become the basic instruments in construction (products of companies were chosen to show the guideline. Other different range products of IT sphere (mobile connection, CCTV monitoring etc.) and products of other fields, e.g. space industry, might be considered as an accessory instrument. Modern technology development allows many ambitious fantasies to come true. It can be options of rendering of the construction process or rendering of building operation. From the author's point of view, in real time, the presence in a 
completed building by immersing potential users into a new artificial function of imitating the world is very useful. This can be realized with a VR-headset, which can be considered as a tool for increasing the interest and, therefore, for sales growth. The so-called geomarketing technology, which allows to make decisions using spatial data in the planning process, deserves special attention and consideration [3]. A large database, accumulated before [4], allows analyzing the indices of a company or a building, having a spatial binding referred to the past, present or future. This allows, for example, to predict the annual turnover of a shopping center located on a certain land plot.

It is verified that partial computerization of some activities is labor-consuming, expensive and, despite of sure effectiveness, often does not meet the expectations [3]. Hence, comprehension of guided tasks integration and all-in-one scalable system creation has come. Insofar as the number of players in the investment and construction sector increases, which actively implement analytical methods in the basis of business, its competence has become important for personnel working with information technology on the project and with it. Consequently, the competence of many advanced managers, leaders and ordinary citizens will constantly grow. "Paper standards" are used for successful use in investment and construction processes for a long time, but in the conditions of dynamic development and the need for rapid adaptation to a changing environment and a more sophisticated tool that allows not only to create but also analyze and predict the process using principles, imitation planning and will become a unique bridge language.

"Information modeling" method could become a language of the investment and construction sector. This technology makes it possible to create an exact digital virtual model of a building [5]. It contains not only geometrical information about objects, but also other necessary data such as costs, terms etc. The result of a building simulation by BIM is a computer model i.e. a database which describes an object itself and the process of its construction that makes possible to get valid project documents timely [6] and assures the increase of construction document coordination level, provides the possibility for more detailed analysis and control. (see fig. 1)

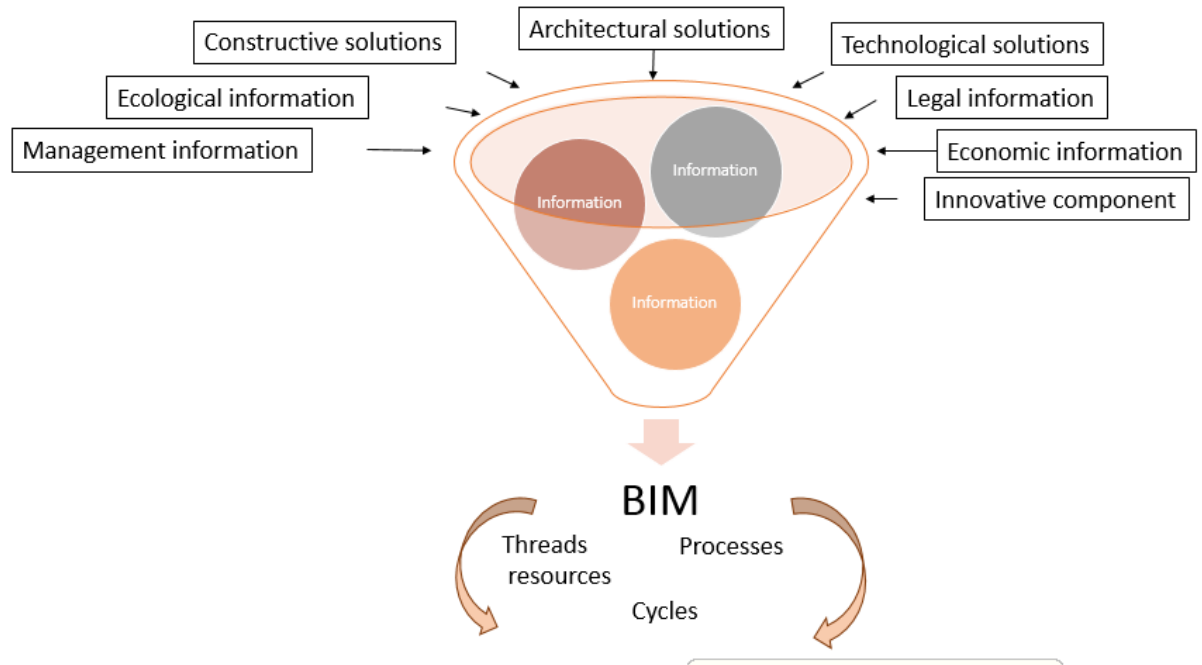

Fig. 1. Integration information model

In other words, this database contains all available information (both external relating to a real estate item and internal) and it is visually presented as information model of life cycle stage and phase that fits many software packages, providing real estate life cycle with 
effective management [7]. Previously developed project management methods and instruments fail to meet usage requirements. By the fact that there is no direct link between project's technical data, cost and time characteristics (it is required to estimate manually, hard to check) many instruments has elements of subjectiveness. This is due to the fact that many indices were taken at the discretion of the expert without proper justification, but the expert's experience (or lack of experience) was taken into account. This is often used to lead to a deviation from the timeline of both time and cost. That is why information modeling technology is not just software or a software package, but a way of organizing the project information that includes tools for cooperation of all stakeholders in the creation and operation of real estate [8]. Such an approach should form a culture of cooperation between participants in the investment and construction sector and build a common information area that allows managing costs, quality and terms of the construction processes $[9,10]$.

\section{Discussion}

In spite of active government programs, the companies of investment and construction sector slowly introduce information modeling in processes of the company and project management. It occurs due to the following reasons: the programs are complicated to use, there is a lack of technology development, insignificant influence on effectiveness and other important factors. Therefore, it is possible to assume that companies are not ready or cannot see any significant advantages of technology implementation. The main goal of this direction is to develop software for economical maintenance of the investment and construction projects. Fulfilment of the information modeling technology aims capitalization of the project. Development of information technology and software market in the investment and construction field requires to create the system for economical, law and organization relations at the intersections of traditional work and services and information technologies.

\section{Conclusion}

The truth is that it is impossible to guarantee the management of the life cycle of real estate outside the digital world under conditions of high uncertainty. The existing conceptual approaches will inevitably require geoinformation correction in order to tackle the problems of lagging in all aspects of construction. The information revolution is stated to occur in conjunction with evolution of the construction sector and affect not so much in the material as the information component of the investment and construction system.

\section{References}

1. M. Ivanova. Futurologist described 2020, 6 (2008)

2. N.Y. Yaskova. Scientific survey, 9, 505-507 (2013)

3. V.M. Markelov. State Councillor: Magazine, 4, 34-38 (2013)

4. N.Y. Yaskova. Real estate: economic, management, 1-2, 52-61 (2013)

5. E.V. Sudov, A.I. Levin. R\&D center for CALS- technologies «Applicable logistics», Moscow, (2002)

6. C.M. Eastman, Engineers and Contractors, 8, (2008) 
7. A. Edgar. National BIM Standard Version 1 Part 1 - Overview, Principles, \& Methodologies, (2007)

8. N.Y. Yaskova, O.V. Murashova. Scientific survey, 9, 160-165 (2013)

9. B. Hardin. BIM and Construction Management: Proven Tools, Methods, and Workflows, (2007)

10. J.M. Cooksey, The integration of building information modeling (BIM) into civil engineering curricula, (2007) 